\title{
A one season prospective cohort study of volleyball injuries
}

\author{
E A L M Verhagen, A J Van der Beek, L M Bouter, R M Bahr, W Van Mechelen
}

Br J Sports Med 2004;38:477-481. doi: 10.1136/bjsm.2003.005785

See end of article for authors' affiliations .....................

Correspondence to: Dr Willem van Mechelen, VU University Medical Centre, VU University Medical Centre

Department of Social Medicine and EMGO Institute, Van der Boechorstrstraat 7, NL1081 BT Amsterdam, Netherlands;

w.vanmechelen@vumc.nl

Accepted 16 July 2003

\begin{abstract}
Objective: To estimate the overall incidence of acute and overuse volleyball injuries, and to describe factors associated with ankle sprains.

Methods: 486 players from the second and third Dutch national volleyball divisions participated in the study and were followed prospectively during a whole season. Three measurements were made during the season (baseline, follow up 1, and follow up 2), where all players completed a questionnaire on demographic variables (only at baseline), sports participation, use of preventive measures, and previous injuries. Volleyball exposure during training and matches was recorded for each individual player by the coach on a weekly exposure form. In case of injury the coach provided the injured player with an injury registration form, which had to be completed within one week after the onset of injury.

Results: 100 injuries were reported, resulting in an overall injury incidence of 2.6 injuries/1000 hours. The incidence of acute injuries was $2.0 / 1000$ hours. Ankle sprains $(n=41)$ accounted for most of the acute injuries, and 31 (75\%) of all players with an ankle sprain reported a previous ankle sprain. Twenty five overuse injuries were reported. The overall incidence of overuse injuries was $0.6 / 1000$ hours; the back and the shoulder were the most common sites.

Conclusions: Ankle sprain is the most common injury in volleyball, accounting for $41 \%$ of all volleyball related injuries. Previous injury seems to be an important risk factor for an ankle sprain. Injury prevention programmes should focus on ankle sprains and concentrate on players with previous ankle sprains.
\end{abstract}

$\mathrm{V}$ olleyball is one of the most popular sports in the world. It is played by approximately 200 million players worldwide. ${ }^{1}$ Despite the popularity and the large number of players there have been surprisingly few prospective reports on volleyball injuries and their prevention. ${ }^{2}$ As volleyball is a non-contact game, where players from the opposing teams are separated by a net, the incidence of injuries might be expected to be low. Nevertheless, volleyball is a sport involving rapid and forceful movements of the body as a whole, both horizontally and vertically, and because of the large forces involved in such movements it is inevitable that injuries occur. ${ }^{3}$ De Loës, ${ }^{4}$ for instance, found in a three year prospective study that-with an injury incidence of 3.0 per 1000 hours - volleyball is the eighth most injury prone sport in the age group 14 to 20 years. Schafle et al found an overall injury incidence of 2.3 per 1000 hours during the United States Volleyball Association's six day national tournament, ${ }^{5}$ while in Norwegian elite volleyball players an incidence of 1.7 per 1000 hours has been reported. ${ }^{6}$

An important purpose of sports injury epidemiology is to supply information about injuries that occur frequently and have serious consequences, and to describe their aetiology, in order to provide a basis for preventive measures. ${ }^{7}$ In view of the global participation rate and the relatively high incidence of volleyball injuries when comparing volleyball with high intensity contact sports, preventive measures are definitely warranted in volleyball. Studies on volleyball injury incidence during training and match play, however, have mainly been retrospective, and reliable information from season-long prospective studies is scarce. ${ }^{2568-12}$ From these previous studies on volleyball injuries it is known that ankle sprains account for up to half of all acute injuries, with an estimate of one sprain per 1000 playing hours. Consequently, preventive strategies should focus mainly on this injury type.

Our aim in the present study was to examine the overall incidence of volleyball injuries, both acute and chronic, and to describe the factors associated with ankle sprains. For this purpose a season long prospective cohort study in a population of competitive volleyball players was used.

\section{METHODS \\ Population}

One hundred and forty four teams (50\% of all Dutch second and third division teams) were invited to participate in our prospective cohort study. From these, 50 teams (20 male, 30 female) consisting of 486 players agreed to participate. The coaches of all participating teams were informed face to face of the purpose and procedures of the study. The study was approved by the medical ethics committee of the VU University Medical Centre, Amsterdam, Netherlands, and written informed consent was given by each participating player.

\section{Design and measurements}

At the start of the season (September 2001) all players completed a questionnaire on demographic variables, sports participation (volleyball and other sports), the use of preventive measures, and previous injuries. This questionnaire (except for the demographic variables) was repeated in January 2002 (follow up 1), and again at the end of the season (May 2002, follow up 2). In order to be included, players had to be free from injury at the start of the study.

Exposure was recorded by the coach on an exposure form. Coaches noted the total duration of each training session and match, and classified the level of participation of each player (that is, in terms of full, three quarters, one half, one quarter, or no participation). If the player did not participate fully, the coach noted the reason-that is, being injured, ill, or absent for other reasons. Completed exposure forms were returned on a weekly basis. Owing to the amount of data coaches had to report during each training and match session, it was inevitable that there would be incomplete exposure forms. Incomplete forms were immediately followed up by a phone reminder. Finally, for all but six teams all exposure forms were collected completely. 
In case of injury the coach provided the injured player with an injury registration form, which had to be completed within one week after the onset. On this form the player was asked to provide information on the injury location, injury type, diagnosis of the injury, direct cause of the injury, preventive measures used at the time of the injury, first aid given, and subsequent medical treatment. If an injury was noted on the exposure form and no injury registration form had been received within two weeks after the injury was logged, the coach was contacted and urged to let the player complete the injury registration form.

\section{Injury definition}

An injury was recorded if it occurred as a result of volleyball and caused the subject to stop this activity, or resulted in the subject not participating fully in the next planned sports activity. All recorded injuries were independently diagnosed as being either acute (that is, resulting from a sudden event during organised volleyball) or overuse (resulting from volleyball, but without a sudden event leading to injury) by two certified sports physicians of the Dutch Volleyball Association, using the injury registration forms. Both physicians had formerly been the Dutch national teams' physician and had considerable knowledge of volleyball injuries. In a consensus meeting, the two physicians tried to reach agreement on injuries which they had classified differently. If no accord was reached a third sports physician would make the final decision. This latter situation, however, did not occur.

\section{Analysis}

For each of the 94 non-participating teams the number of players, their sex, age, and volleyball experience, and the number of registered players in the club were tracked through the administration of the Dutch Volleyball Association for a non-response analysis.

Injury incidence was calculated for all participants and for men and women separately, as the number of new injuries reported per 1000 hours of play (total, match, or training, as appropriate), using exposure time of each individual player until the onset of first injury. For each injury category-that is, chronic or overuse-injury incidence was calculated using exposure time of each individual player until the onset of the first injury of this category. For match compared with training, and for men compared with women, relative injury risk (RR) and corresponding 95\% confidence interval (CI) were calculated. Where possible odds ratios (OR) and the corresponding 95\% CI were calculated for the factors associated with ankle sprains.

Recorded exposure and injury data of players without complete follow up were included in the analyses until they dropped out of the study. As exposure sheets provided hours of volleyball participation and served as a control for the registration of injuries, players had to be excluded from further analyses once exposure data of their team were missing.

\section{RESULTS}

The non-response analysis showed that significantly more male than female teams did not participate in the study. For the other variables (that is, the number of players, age, volleyball experience, and the number of registered players in the club), no significant differences were found (data not shown). Of the 50 teams that agreed to participate in the study, nine dropped out after four months (that is, at follow up 1), and another three after nine months (at follow up 2). Baseline variables of these 12 teams did not differ from those of the other teams (data not shown). Exposure data were missing for four male and two female teams. Consequently these teams were excluded from the analyses. Baseline variables for these six excluded teams did not differ from the other teams (data not shown). All the players from the participating teams reported that they were free from injury at baseline. This resulted in a baseline sample of 44 teams with 419 volleyball players (158 men and 261 women) (table 1).

A total exposure of 44891 hours was reported throughout the 36 week season, during which 100 injuries occurred (table 2). With a relative risk of 2.3 (95\% CI, 1.5 to 3.7 ), the overall risk of injuries was higher for match play than for training. No differences between men and women were found for total, training, and match injury incidence. The overall mean (SD) absence from volleyball after injury was 4.3 (4.6) weeks. For men and women the mean absence was, respectively, 4.1 (5.7) weeks and 4.4 (3.5) weeks (NS).

With a total of 78 acute injuries, the acute injury incidence was 2.0 (95\% CI, 1.5 to 2.4 ) per 1000 hours (table 3). With a relative risk of 2.4 ( 1.4 to 3.8 ) the risk of acute injuries was higher for match play than for training. The mean absence from volleyball after an acute injury was 4.0 (3.8) weeks. In terms of acute injuries, the lower extremity was the most commonly injured body region, with 65 injuries (83\% of all acute injuries). Ankle injuries $(n=41)$, all sprains, accounted for most of these. The risk of ankle sprain did not differ between match and training, or between men and women.

During the season 25 overuse injuries were reported (table 3). The overall incidence of overuse injuries was 0.6 (0.4 to 0.8 ) per 1000 hours. The mean absence from volleyball because of an overuse injury was 4.0 (6.2) weeks, with the shoulder causing the longest absence (6.2 (9.4) weeks), followed by the knee (2.9 (1.8) weeks). While there were very few acute shoulder injuries, these injuries accounted for $32 \%$ of the overuse injuries. Back (32\%) and knee injuries (20\%) were the other main overuse injury types.

With an absolute number of 41 injuries and an incidence 1.0 (0.7 to 1.3$)$ per 1000 hours, ankle sprain was the most common injury type. In all, 25 ankle sprains were sustained in the net zone (61\%) (fig 1). The odds ratio for ankle sprains sustained in the net zone versus the backfield was 2.0 (0.7 to 5.8). Of all ankle sprains that occurred in the net zone, most occurred in contact with either a team mate or an opponent after a defensive action-for example, a block (fig 2).

Three of the players (7\%) were wearing ankle protection at the time of injury, while $31(75 \%)$ of the injured players reported to have sustained a previous ankle sprain. Of these previous sprains, 11 (25\%) were sustained within 12 months preceding the recurrence of the ankle sprain (fig 3). The odds ratio of recurrent ankle sprains within 12 months versus "fresh" ankle sprains was 1.9 (0.8 to 4.7$)$. The overall mean absence from volleyball after an ankle sprain was 4.5 (3.6) weeks.

\section{DISCUSSION}

This one season prospective study showed an overall volleyball injury incidence of 2.6 per 1000 playing hours. The overall incidence for training related injuries was 1.8 per 1000 playing hours, and for match related injuries, 4.1. Differences in study design, player population, and injury definition

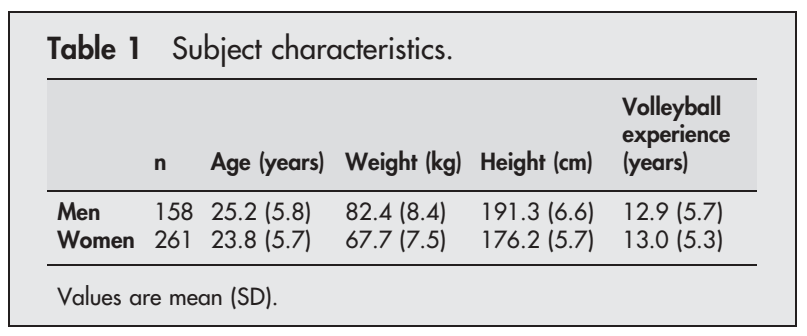


Table 2 Volleyball exposure, the number of injuries, and injury incidence (95\% confidence interval) during the 2001 to 2002 indoor season

\begin{tabular}{|c|c|c|c|c|c|c|c|c|c|}
\hline & \multicolumn{3}{|l|}{ Total } & \multicolumn{3}{|l|}{ Training } & \multicolumn{3}{|l|}{ Match } \\
\hline & Exposure (h) & Injuries (n) & $\begin{array}{l}\text { Incidence } \\
\text { (n/1000 h) }\end{array}$ & Exposure (h) & Injuries (n) & $\begin{array}{l}\text { Incidence } \\
\text { (n/1000 h) }\end{array}$ & Exposure (h) & Injuries (n) & $\begin{array}{l}\text { Incidence } \\
\text { (n/1000 h) }\end{array}$ \\
\hline Men* & 14867 & 44 & $3.0(2.1$ to 3.9$)$ & 12193 & 28 & 2.3 (1.5 to 3.2$)$ & 3974 & 15 & 3.8 (1.9 to 5.7$)$ \\
\hline Women† & 23245 & 56 & $2.4(1.8$ to 3.0$)$ & 18331 & 27 & $1.5(0.9$ to 2.0$)$ & 6392 & 27 & $4.2(2.6$ to 5.8$)$ \\
\hline Total & 38112 & 100 & $2.6(2.1$ to 3.1$)$ & 30524 & 55 & $1.8(1.3$ to 2.8$)$ & 10367 & 42 & $4.1(2.8$ to 5.3$)$ \\
\hline
\end{tabular}

*One injury could not be traced as being either training or match related.

†Two injuries could not be traced as being either training or match related.

between the present study and previous studies complicate the comparison of incidence figures. Nevertheless, incidences found in the present study seem similar to those previously found in other studies. From a one season retrospective study in the Danish elite division, Aagaard and Jørgensen ${ }^{8}$ reported an overall volleyball injury incidence of 3.8 per 1000 playing hours. In a six day prospective study in the USVBA National Tournament, Schafle et al estimated the overall injury incidence to be 2.3 per 1000 playing hours, when only injuries causing at least one day of missed participation were included. ${ }^{5}$ Bahr and Bahr, ${ }^{6}$ using a similar injury definition and study design as the present study, found the incidence of acute injuries to be 1.7 per 1000 playing hours in a prospective one season study.

Consistent with previous studies we found the injury risk to be significantly higher during match play than during training. ${ }^{2}{ }^{13}$ It has been suggested that this is because of a higher intensity of play, and more risks being taken during matches. $^{25}$

With an incidence of 1.0 per 1000 playing hours in the present study, ankle sprains were by far the most common type of injury in volleyball. This result is supported by findings from previous epidemiological studies. ${ }^{23569}$ In our study ankle injuries accounted for roughly $40 \%$ of all injuries (acute and overuse) and for $52 \%$ of all acute injuries. This is in accordance with other studies, showing the proportion of ankle sprains to be between one quarter and one half of all acute injuries in volleyball. ${ }^{510-12}$

Although the absolute number of ankle sprains in our study was low, resulting in low power for statistical analyses to identify risk factors, we found some factors associated with ankle sprains. In the present study, $61 \%$ of all ankle sprains occurred at the net zone, and from these the majority (59\%) happened during contact with either a team mate or an opponent while landing after attacking or blocking. From earlier studies it is also known that the two main risk factors for ankle sprains in volleyball are players landing on the foot of an opponent in the conflict zone under the net, or a player landing on the foot of a team mate after a two man block. ${ }^{2}{ }^{6}$ Another important finding is that the risk of injury was higher after a previous ankle sprain. From our results it can be seen that the shorter the time since the previous sprain, the greater the risk for reinjury. Therefore our study provides strong evidence that players have an increased risk for reinjury after a previous ankle sprain, especially during the first year post-injury. These findings are supported by other studies in volleyball, ${ }^{26}$ as well as in other sports. ${ }^{14}{ }^{15}$

In our study knee injuries accounted for $12 \%$ of all injuries. Although knee injuries are not the most frequent injuries seen in volleyball, these types of injury are of increasing concern in various sports. This is mainly a reflection of the comparatively high incidence of anterior cruciate ligament (ACL) injuries among women in some sports. It has been suggested that female volleyball players are at much higher risk for ACL knee injuries than male players, ${ }^{13}$ but our study and some other studies ${ }^{810}$ did not find such a sex difference. This could mean that the overrepresentation of female knee injuries seen in other sports-for example, handball, ${ }^{16}{ }^{17}$ skiing, ${ }^{18}$ basketball, ${ }^{19}$ and soccer ${ }^{19}$-is not present in volleyball.

Although the population of the study was large, there was a considerable number of non-responders. Of the 144 invited teams, only 50 participated. While a non-response analysis showed no differences between the participating and the non-participating teams, there is still a chance of a selection bias. Because information gathered for the non-response analysis was rather limited (that is, the number of players per team, the sex, age, and volleyball experience of players, and the number of registered players in the club), it is unknown to what extent factors such as level of play may have biased

Table 3 Number of injuries, injury incidence (95\% confidence interval), and absence from volleyball because of injury (number of weeks, mean (SD)), given by injury location

\begin{tabular}{|c|c|c|c|c|c|c|c|c|c|}
\hline & \multicolumn{3}{|c|}{ Overall } & \multicolumn{3}{|c|}{ Acute } & \multicolumn{3}{|c|}{ Overuse } \\
\hline & \multicolumn{2}{|c|}{ Injuries } & \multirow{2}{*}{$\begin{array}{l}\text { Absence } \\
\text { (weeks) }\end{array}$} & \multicolumn{2}{|c|}{ Injuries } & \multirow{2}{*}{$\begin{array}{l}\text { Absence } \\
\text { (weeks) }\end{array}$} & \multicolumn{2}{|c|}{ Injuries } & \multirow{2}{*}{$\begin{array}{l}\text { Absence } \\
\text { (weeks) }\end{array}$} \\
\hline & $n$ & $\mathrm{n} / 1000 \mathrm{~h}$ & & $\bar{n}$ & $\mathrm{n} / 1000 \mathrm{~h}$ & & $\bar{N}$ & $\mathrm{n} / 1000 \mathrm{~h}$ & \\
\hline Ankle & 41 & $1.0(0.7$ to 1.3$)$ & $4.5(3.6)$ & 41 & $1.0(0.7$ to 1.3$)$ & $4.5(3.6)$ & 0 & - & - \\
\hline $\begin{array}{l}\text { Knee }^{*} \\
\text { Other lower }\end{array}$ & 12 & $0.3(0.1$ to 0.4$)$ & $3.8(3.0)$ & 5 & $0.1(0.0$ to 0.2$)$ & $4.0(2.6)$ & 5 & $0.1(0.0$ to 0.2$)$ & $2.9(1.8)$ \\
\hline extremity† & 21 & $0.5(0.3$ to 0.7$)$ & $3.1(4.0)$ & 19 & $0.4(0.2$ to 0.6$)$ & $3.2(4.0)$ & 4 & $0.1(0.0$ to 0.2$)$ & $1.8(1.1)$ \\
\hline Back $\ddagger$ & 10 & $0.2(0.1$ to 0.4$)$ & $2.8(1.5)$ & 5 & 0.1 (0.0 to 0.2$)$ & $2.2(1.6)$ & 8 & $0.2(0.1$ to 0.3$)$ & 2.4 (1.2) \\
\hline $\begin{array}{l}\text { Shoulder } \\
\text { Other upper }\end{array}$ & 9 & $0.2(0.1$ to 0.3$)$ & $7.9(10.1)$ & 1 & $0.0(0.0$ to 0.1$)$ & $9.5(-)$ & 8 & $0.2(0.1$ to 0.3$)$ & $6.2(9.4)$ \\
\hline extremity & 7 & $0.2(0.0$ to 0.3$)$ & $2.8(1.9)$ & 7 & $0.2(0.0$ to 0.3$)$ & $2.6(1.9)$ & 0 & - & - \\
\hline Total & 100 & $2.6(2.1$ to 3.1$)$ & $4.2(4.6)$ & 78 & 2.0 (1.5 to 2.4$)$ & $4.0(3.8)$ & 25 & $0.6(0.4$ to 0.8$)$ & $4.0(6.2)$ \\
\hline
\end{tabular}

*Information of two injuries was insufficient to be diagnosed as either acute or overuse.

tTwo players reported an acute and an overuse lower extremity injury during the study. For overall injury incidence only the first of these injuries was taken into account.

$\ddagger$ Three players reported an acute and an overuse back injury during the study. For overall injury incidence only the first of these injuries was taken into account. 


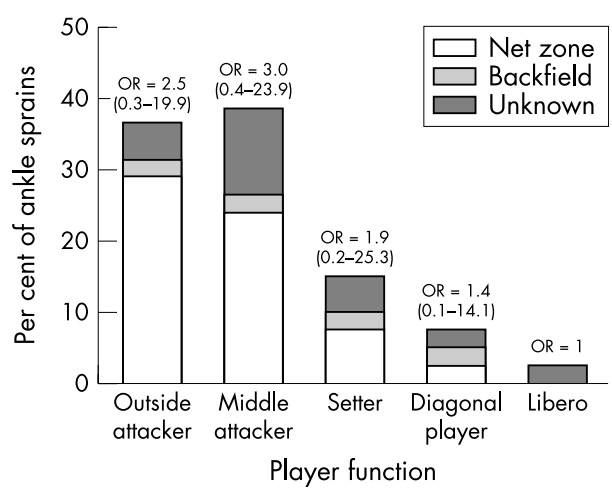

Figure 1 Ankle sprains by player function and court position at the time of injury $(n=41)$. Odds ratios (OR) with $95 \%$ confidence intervals are calculated using the "no previous injury" group as reference.

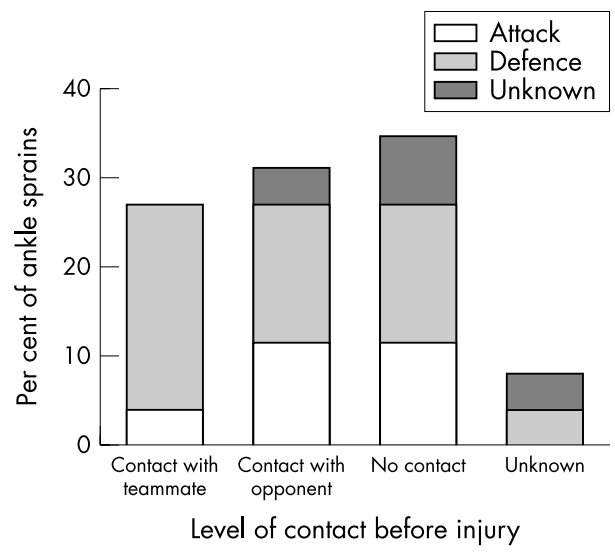

Figure 2 Ankle sprains sustained at the net zone $(n=25)$, by activity and contact with other players when injured.

the results. However, the non-participating teams were uniformly divided over the final competition rankings and regions. Therefore we believe that our study may be seen as a random sample of teams and that the likelihood of selection bias is small.

As baseline variables of the 12 teams that dropped out of the study did not differ from the other teams included, and only five teams dropped out for reasons unknown, the likelihood of selective drop out is also small.

The strength of this study was that information on training and match participation of each individual player was gathered through the use of exposure forms that were returned on a weekly basis. In addition to the duration of training sessions and matches, it was also noted whether a player was absent from training or match play and whether this absence was because of an injury. We therefore believe that nearly all injuries affecting sports participation have been reported. The drawback of this method of collecting injury data was that if exposure sheets were missing for a team, injuries were not recorded either. For this reason the six teams that had missing exposure sheets had to be excluded from the analyses. Another limitation may be that the injury registration was limited to injuries that caused the player to stop playing. This may have led to an underestimation of overuse injury incidence-the so called "tip of the iceberg" phenomenon. ${ }^{20}$ Many overuse injuries produce pain and discomfort but do not necessarily cause a player to stop playing. Where other studies in volleyball have shown,

\section{What is already known on this topic}

- Despite the non-contact nature of volleyball, this sport has a high injury incidence. Previous studies on volleyball injuries have shown that ankle sprains account for up to one half of all acute injuries in volleyball, with an estimate of one sprain per 1000 playing hours.

\section{What does this study add}

- Studies on volleyball injury incidence during training and match play have mainly been retrospective, and reliable information from season-long prospective studies is scarce. The current study overcomes the drawbacks of the few previous prospective studies, and thereby strengthens data and theories from previous work.

for instance, a relatively high incidence of overuse knee injuries, ${ }^{59}$ the present study failed to do so. The most likely explanation is that patellar tendon overuse injuries (jumper's knee) do not necessarily cause absence from volleyball. ${ }^{21-23}$ Previous reports also suggest that overuse shoulder injuries may be more common in volleyball than we found in the present study. ${ }^{2425}$ In addition, one should realise that acute injuries do not always cause absence from play. This was shown, for instance, in the small number of finger injuries found in the present study. Although finger sprains are frequent in volleyball, and in some studies even as common as ankle sprains, ${ }^{926}$ they rarely cause loss of time from training or games.

\section{Conclusions}

The overall injury incidence in volleyball was 2.6 per 1000 playing hours. The incidence of acute and overuse injuries was 2.0 and 0.6 per 1000 playing hours, respectively. The ankle sprain is clearly the most common injury in volleyball, accounting for $41 \%$ of all volleyball related injuries, with an injury incidence of 1.0 per 1000 playing hours. Although our study was limited to injuries causing absence from volleyball, ankle sprains should be of particular interest in studies on prevention strategies. Previous injury seems to be an important risk factor for ankle sprains. Thus if an initial ankle sprain can be prevented the most important risk factor has been eliminated.

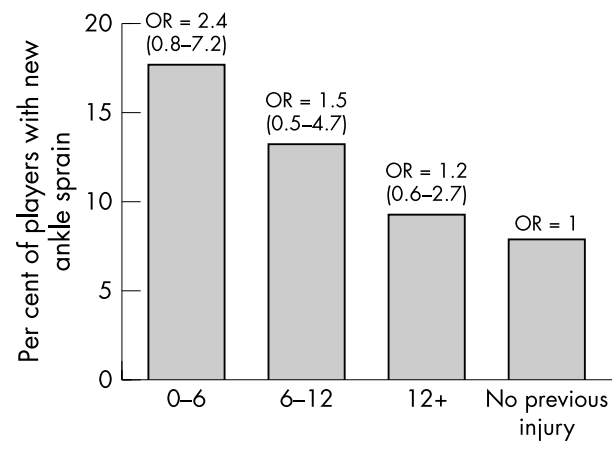

Time since previous ankle sprain (months)

Figure 3 Risk of recurrent ankle sprains as a percentage of players injured in each group. Odds ratios (OR) with $95 \%$ confidence intervals are calculated using the "no previous injury" group as reference. 


\section{ACKNOWLEDGEMENTS}

This study was financially supported by the Netherlands Organisation for Health Research and Development (ZonMw; grant No 2200.0068), and the project group Sport Blessure Vrij (SBV) of the Dutch National Olympic Committee (NOC*NSF). We would also like to thank the Dutch Volleyball Association for their cooperation and specifically R H M Vesters MD and $\mathrm{H} \mathrm{J} \mathrm{P} \mathrm{A} \mathrm{du} \mathrm{Bois} \mathrm{MD} \mathrm{for} \mathrm{their}$ willingness to give their expertise by diagnosing all registered injuries, and their help in the organisation of the study. We are also very grateful with the help given by $\mathrm{M}$ Inklaar in collecting the data.

\section{Authors' affiliations}

E A L M Verhagen, L M Bouter, W Van Mechelen, Institute for Research in Extramural Medicine and Body@work TNO-Vumc, Amsterdam, Netherlands

A J Van der Beek, Institute for Research in Extramural Medicine and TNO Vumc, Amsterdam

R M Bahr, Norwegian University of Sport and Physical Education, Oslo, Norway

W van Mechelen, VU University Medical Centre, Amsterdam

\section{REFERENCES}

1 Federation Internationale de Volleyball (FIVB). Lausanne: X-Press 47, 1994 (Jan): 1.

2 Bahr R, Karlsen R, Lian $\varnothing$, et al. Incidence and mechanisms of acute ankle inversion injuries in volleyball. A retrospective cohort study. Am J Sports Med 1994;22:595-600.

3 Watkins J, Green BN. Volleyball injuries: a survey of injuries of Scottish National League male players. Br J Sports Med 1992;26:135-37.

4 De Loës M. Epidemiology of sports injuries in the Swiss organization "Youth and Sports" 1987-1989: injuries, exposures and risks of main diagnosis. Int J Sports Med 1995; 16:134-8.

5 Schafle MD, Requa RK, Patton WL, et al. Injuries in the 1987 National Amateur Volleyball Tournament. Am J Sports Med 1990;18:624-31.

6 Bahr R, Bahr IA. Incidence of acute volleyball injuries: a prospective cohort study of injury mechanisms and risk factors. Scand J Med Sci Sports 1997:7:166-71.

7 Van Mechelen W, Hlobil H, Kemper HCG. Incidence, severity, aetiology and prevention of sports injuries. A review of concepts. Sports Med 1992;14:82-99.
8 Aagaard H, Jørgensen U. Injuries in elite volleyball. Scand J Med Sci Sports 1996;6:228-32.

9 Aagaard H, Scavenius M, Jørgensen U. An epidemiological analysis of the injury pattern in Indoor and Beach Volleyball. Int J Sports Med 1997; 18:217-21.

10 Gerberich SG, Luhman S, Finke C, et al. Analysis of severe injuries associated with volleyball activities. Phys Sports Med 1987;15:75-9.

11 Yde J, Nielsen AB, Epidemiological and traumatological analyses of injuries in a Danish volleyball club. Ugeskr Læger 1988;150:1022-3.

12 Solgärd L, Nielsen AB, Møller-Madsen B, et al. Volleyball injuries presenting in casualty: a prospective study. Br J Sports Med 1995;29:200-4.

13 Ferretti A, Papendrea P, Conteduca F. Knee injuries in volleyball. Sports Med 1990;10:132-8.

14 Ekstand J, Tropp H. The incidence of ankle sprains in soccer. Foot Ankle 1990;11:41-4.

15 Milgrom C, Shlamkovitch N, Finestone A, et al. Risk factors for lateral ankle sprains: a prospective study among military recruits. Foot Ankle $1991 ; 12: 26-30$.

16 Jørgensen U. Epidemiology of injuries in typical Scandinavian team sports. Br J Sports Med 1984;18:59-63.

17 Myklebust G, Maehlum S, Engebretsen L, et al. A prospective cohort study of anterior cruciate ligament injuries in elite Norwegian team handball. Scand J Med Sci Sports 1998;8:149-53.

18 Sylvest A, Lund NA, Lauritzen JB, et al. Skiing injuries among Danes in Austria. Scand J Med Sci Sports 1991;1:225-7.

19 Arendt E. Dick R. Knee injury patterns among men and women in collegiate basketball and soccer; NCAA data and review of the literature. Am J Sports Med 1995;23:694-701.

20 Walter S, Sutton J, Mclntosh J, et al. The aetiology of sports injuries. A review of methodologies. Sports Med 1985;2:47-58.

21 Lian $\varnothing$, Holen KJ, Engebretsen L, et al. Relationship between symptoms of jumper's knee and the ultrasound characteristics of the patellar tendon among high-level male volleyball players. Scand J Med Sci Sports 1996:6:291-6.

22 Ferretti A, Puddu G, Mariani PP, et al. Jumper's knee: an epidemiological study of volleyball players. Phys Sports Med 1984;12:97-103.

23 Kujala UM, Friberg O, Aalto T, et al. Lower limb asymmetry and patellofemoral joint incongruence in the etiology of knee exertion injuries in athletes. Int J Sports Med 1987;8:214-20.

24 Ferretti A, Cerullo G, Russo G. Suprascapular neuropathy in volleyball players. J Bone Joint Surg Am 1987;69A:260-3.

25 Holzgraefe M, Kukowski B, Eggert S. Prevalence of latent and manifest suprascapular neuropathy in high-performance volleyball players. $\mathrm{Br} J$ Sports Med 1994; 28:177-9

26 Bhairo NH, Nijsten MWN, Van Dalen KC, et al. Hand injuries in volleyball. Int J Sports Med 1992;13:351-4. 